\title{
PREFERENSI DAN PERSEPSI WISATAWAN MANCANEGARA KE NUSA PENIDA, KLUNGKUNG
}

\author{
Dewa Ayu Putu Putri Krisnadevi ${ }^{1}$, I Nyoman Sudiarta ${ }^{2}$, I Ketut Suwena ${ }^{3}$ \\ ${ }^{1}$ Email :dewaayuina26@gmail.com \\ Program Studi S1 Industri Perjalanan Wisata, Fakultas Pariwisata, Universitas Udayana \\ ${ }^{2}$ Email : sudiarta.nyoman@yahoo.co.id \\ Program Studi S1 Industri Perjalanan Wisata, Fakultas Pariwisata, Universitas Udayana \\ ${ }^{3}$ Email : suwena_ketut@yahoo.co.id \\ Program Studi S1 Industri Perjalanan Wisata, Fakultas Pariwisata, Universitas Udayana
}

\begin{abstract}
The increasing tourist attraction of tourists must be adjusted to the availability of tourism facilities, such as attractions, Facilities, Infratructure, Transportation, and Hospitality (AFITH). Therefore, tourism stakeholders are important to know what the tourists are interested in and preferred or better known for their preference. This research aims to determine the preferences and perception of foreign tourists when visiting Nusa Penida, Klungkung. The analysis techniques that used are quantitative descriptive with the calculation of cross and chi-square tabulation analysis and also use of Likert scale gauge to measure the perception of foreign tourists that visiting Nusa Penida, Klungkung. Respondents determined by an Accidental samplingtechnique 90 peoples of foreign tourists that visiting Nusa Penida, Klungkung. The characteristic of foreign tourists on this research dominated by male tourist in 26-35 years old, dominated by Germany's tourist, with the education level dominated by bachelor, as an employee, and the status is single, which aims to holiday with a source of information on Internet/social media, long stay 3-4 days, first time visit, and expressed willing to visit Nusa Penida, Klungkung again in another opportunity. The preference of foreign tourists when visiting Nusa Penida is divided into several preferences such as tourist attractions are natural attractions, on the preferences of accommodation facilities, foreign tourists choose a homestay, and then the tourist prefer to choose a warung or traditional stalls, and the transportation that choosen by the tourist is motorcycle. Perception of tourists to infrastructure that includes network communication and availability of clean water, the perception of tourists to the road conditions in Nusa Penida is not good, perception of tourists towards Hospitality in tourist attractions, Hospitality in the accommodation, and local community Hospitality expressed well.
\end{abstract}

\begin{abstract}
Abstrak: Meningkatnya kunjungan wisatawan pada suatu daya tarik wisata tentu harus disesuaikan dengan ketersediaan sarana wisata, seperti Attractions, Facilities, Infratructure, Transportation, dan Hospitality (AFITH). Untuk itu stakeholder pariwisata penting mengetahui apa yang diminati dan disukai wisatawan atau yang lebih dikenal dengan preferensi wisatawan. Penelitian ini bertujuan untuk mengetahui preferensi dan persepsi wisatawan mancanegara ketika berkunjung ke Daya Tarik Wisata Nusa Penida, Klungkung. Teknik analisis data yang digunakan adalah deskriptif kuantitatif dengan perhitungan analisis tabulasi silang dan chi-square dan menggunakan alat ukur dengan skala likert untuk mengukur persepsi wisatawan. Responden ditentukan dengan teknik purposive sampling merupakan wisatawan mancanegara sebanyak 90 orang. Karakteristik wisatawan mancanegara pada penelitian ini, mayoritas adalah wisatawan laki- laki berusia 26- 35 tahun, Negara asal Jerman, pendidikan terakhir sarjana, dengan pekerjaan sebagai pegawai, memiliki status belum menikah, yang bertujuan berlibur dengan sumber informasi dri internet/ media social. Lama tinggal wisatawan 3-4 hari, yang merupakan kunjungan pertama kali, dan menyatakan bersedia untuk berkunjung kembali. Preferensi wisatawan mancanegara ketika berkunjung ke Nusa Penida dibagi menjadi beberapa preferensi antara lain: Atraksi wisata yang lebih diminati adalah wisata alam, pada preferensi fasilitas akomodasi wisatawan mancanegara memilih homestay sebagai tempat tinggal, kemudian fasilitas tempat makan dan minum mayoritas memilih warung, dan transportasi yang lebih diminati adalah motor. Persepsi wisatawan terhadap infrastruktur seperti: jaringan komunikasi dan ketersediaan air bersih baik, persepsi wisatawan terhadap kondisi jalan di Nusa Penida dinyatakan tidak baik, persepsi wisatawan terhadap Hospitality di atraksi wisata, Hospitality di akomodasi, dan Hospitality masyarakat local dinyatakan baik.
\end{abstract}

Keywords: preference, perception, foreign tourist, characterystic, AFITH. 


\section{PENDAHULUAN}

Bidang pariwisata adalah salah satu bidang industri yang semakin lama semakin maju dan pesat perkembangannya. Tren kunjungan wisatawan dunia terutama wisatawan mancanegara mengalami perubahan yang sangat drastis mulai dari motivasi kunjungan, lama kunjungan, periodisasi kunjungan serta pola kunjungan lainnya sampai kepada perilaku berbelanja wisatawan (Choi et al, 2007; Vuuren dan Slabbert, 2011; Budeanu, 2007). Bali merupakan salah satu destinasi pariwisata yang memiliki keunikan tersendiri dibandingkan dengan daerah lain di Indonesia. Salah satu kabupaten yang mulai ramai dikunjungi wisatawan, yang juga dalam proses memajukan kawasankawasan wisatanya adalah Kabupaten Klungkung. Daya tarik wisata yang sangat menonjol adalah daya tarik wisata Nusa Penida saat ini sedang banyak dikunjungi wisatawan. Meningkatnya kunjungan wisatawan harus disesuaikan dengan ketersediaan sarana wisata di Kawasan Nusa Penida. Sarana wisata yang dimaksud adalah akomodasi tempat menginap maupun makan dan minum, atraksi wisata yang ditawarkan daya tarik wisata, Infrastruktur di kawasan parwisata tersebut, Transportasi dan Hospitality yang terdapat di kawasan wisata, sejalan dengan teori AFITH (Attractions, Facilities, Infratructure, Transportation, dan Hospitality) yang dikemukakan oleh Mill and Morrison (2009;17). Preferensi merupakan suatu sikap kecenderungan seseorang dalam menentukan keputusan. Preferensi dan persepsi wisatawan penting diketahui untuk membantu stakeholder pariwisata dalam menciptakan produk wisata baru dan membuat wisatawan lebih nyaman dengan apa yang diinginkan oleh wisatawan itu sendiri. Persepsi wisatawan perlu untuk mengetahui pandangan wisatawan terhadap beberapa komponen pariwisata yang dibutuhkan wisatawan di daya tarik wisata Nusa Penida.

\section{METODE}

Karakteristik wisatawan, preferensi wisatawan, dan persepsi wisatawan adalah variabel utama dalam penelitian ini. Definisi karakteristik berdasarkan trip descriptor yaitu tujuan perjalanan, sumber informasi, lama menginap, frekuensi kunjungan, dan kesediaan berkunjung kembali. Berdasarkan tourist descriptor yaitu kewarganegaraan, jenis kelamin, usia, tingkat Pendidikan, pekerjaan, dan status perkawinan. Preferensi Wisatawan menggunakan tiga indikator dari teori destination mix (AFITH) yaitu atraksi, fasilitas yang dibagi menjadi dua jenis yaitu fasilitas akomodasi dan fasilitas tempat makan dan minum, serta preferensi transportasi. Persepsi Wisatawan diukur dengan dua atribut dari teori destination mix (AFITH) yaitu persepsi infrastruktur dan hospitality di Nusa Penida.

Teknik pengumpulan data yang digunakan yaitu observasi, wawancara, angket, studi kepustakaan, dan dokumentasi,. Teknik pengambilan sampel adalah teknik accidental sampling dengan ketentuan yang dijadikan responden wisatawan mancanegara yang berkunjung ke Nusa Penida. Penelitian ini menggunakan wisatawan mancanegara sebagai responden berjumlah 90orang, dengan menggunakan Teknik penentuan banyak sampel (Supranto, 2006). Informan dalam penelitian ini ada dua, yaitu informan pangkal dan informan kunci.Teknik analisis data yang digunakan deskriptif kuantitatif dengan perhitungan analisis tabulasi silang dengan chi square menggunakan softwere SPSS. Sedangkan pada variable sikap dianalisis dengan cara manual dibantu alat ukur skala likert.

\section{HASIL DAN PEMBAHASAN}

Berdasarkan trip descriptor atau gambaran perjalanan wisatawan, yaitu tujuan mereka datang ke Nusa Penida, Klungkung untuk berekreasi/ berlibur. Wisatawan juga menyatakan mendapat informasi dari internet/ media social, mereka menghabiskan waktu liburan selama 3-4 hari, sebagian besar wisatawan menyatakan baru pertama kali berkunjung ke Nusa Penida, Klungkung. Mayoritas wisatawan mancanegara bersedia berkunjung kembali dikarenakan mereka sangat

Dilihat dari karakteristik wisatawan mancanegara berdasarkan tourist descriptoryang berkunjung ke Nusa Penida, 
Klungkung berasal dari berbagai negara maju dan didominasi oleh wisatawan dari Negara Jerman. Wisatawan mancanegara yang menjadi respondenmayoritas berjenis kelamin laki- laki, dan dari kelompok usia wisatawan berusia 2635 tahun, dengan tingkat Pendidikan terakhir mayoritas bergelar Sarjana. Sebagian besar wisatawan memiliki jenis pekerjaan sebagai pegawai, dengan status belum menikah.

Preferensi wisatawan mancanegara yang berkunjung ke Nusa Penida, Klungkung diklasifikasi menjadi empat preferensi, yaitu preferensi terhadap atraksi wisata, fasilitas akomodasi, fasilitas tempat makan dan minum, dan preferensi transportasi. Preferensi mayoritas wisatawan mancanegara terhadap atraksi wisata yang ada di Nusa Penida adalah atraksi wisata alam, sebagian besar wisatawan manyatakan lebih memilih homestay sebagai fasilitas akomodasi saat berkunjung ke Nusa Penida. Preferensi wisatawan terhadap fasilitas tempat makan dan minum menghasilkan warung sebagai tempat makan dan minum pilihan wisatawan mancanegara. Mayoritas wisatawan mancannegara terhadap pemilihan transportasi ketika berkunjung ke Nusa Penida adalah menggunakan motor.

Persepsi atau penilaian wisatawan mancanegara yang berkunjung ke Nusa Penida terhadap jaringan komunikasi dan ketersediaan air bersih dinilai baik, kemudian penilaian wisatawan terhadap kondisi jalan di Nusa Penida dinyatakan tidak baik dikarenakan masih banyak jalan yang rusak dan dapat membahayakan wisatawan yang lewat. Hasil persepsi wisatawan mancanegara yang berkunjung ke Nusa Penida terkait dengan Hospitality diperoleh hasil Hospitality di atraksi wisata, Hospitality di akomodasi, dan Hospitality masyarakat local dinyatakan tergolong baik.

\section{SIMPULAN DAN SARAN Simpulan}

Karakteristik

wisatawan

berdasarkan trip descriptor yang berkunjung ke Nusa Penida menyatakan bahwa tujuan mereka datang ke Nusa Penida, Klungkung adalah rekreasi atau berlibur, wisatawan mendapat informasi tentang Nusa Penida dominan dari internet dengan lama tinggal di Nusa Penida selama
3-4 hari, merupakan kunjungan pertama kali, dan hampir seluruh wisatawan menyatakan bersedia untuk berkunjung kembali ke Nusa Penida. Kemudian karakteristik wisatawan mancanegara yang berkunjung ke Nusa Penida, Klungkung berdasarkan tourist descriptor atau gambaran mengenai diri wisatawan, diketahui bahwa wisatawan mancanegara yang mendominasi adalah yang berasal dari Negara Jerman,dengan jenis kelamin lakilaki, berusia 26- 35 tahun. Tingkat pendidikan terakhir dicapai adalah dominan lulusan Sarjana dan rata- rata jenis pekerjaan yang dimiliki adalah sebagai pegawai, dengan status wisatawan belum menikah.

Peferensi wisatawan terhadap jenis atraksi wisata yang ada di Nusa Penida adalah dominan lebih menyukai atraksi wisata alam, dalam hal jenis fasilitas akomodasi wisatawan mancanegara lebih menyukai menginap di homestay di Nusa Penida. Preferensi wisatawan mancanegara terhadap fasilitas tempat makan dan minum adalah warung local di Nusa Penida, dan preferensi wisatawan mancanegara terhadap jenis transportasi ketika berada di Nusa Penida adalah menggunakan motor.

Persepsi wisatawan mancanegara yang berkunjung ke Nusa Penida terhadap beberapa elemen destinasi wisata di Nusa Penida meliputi Infrastruktur (jaringan komunikasi, ketersediaan air bersih, dan kondisi jalan) dan Hospitality (Hospitality di atraksi wisata, Hospitality di akomodasi, dan Hospitality masyarakat local). Dimana diperoleh hasil penilaian wisatawan mancanegara ketika berkunjung ke Nusa Penida terhadap jaringan komunikasi dan ketersediaan air bersih dinilai baik, penilaian wisatawan terhadap kondisi jalan di Nusa Penida dinyatakan tidak baik dikarenakan masih banyak jalan yang rusak dan dapat membahayakan wisatawan yang lewat. Hasil persepsi wisatawan mancanegara yang berkunjung ke Nusa Penida terkait dengan Hospitality diperoleh hasil terhadap Hospitality di atraksi wisata, 
Hospitality di akomodasi, dan Hospitality masyarakat local dinyatakan tergolong baik.

\section{Saran}

Pemerintah dapat memberikan perhatian lebih untuk pengembangan pariwisata di Nusa Penida seperti adanya peningkatan fasilitas penunjang kegiatan pariwisata di Nusa Penida. Pengelola pariwisata meningkatkan pelayanan dan kesadaran akan kebersihan di Nusa Penida agar wisatawan lebih nyaman tinggal di Nusa Penida. Masyarakat lokal di Nusa Penida lebih ramah kepada wisatawan yang berkunjung ke Nusa Penida, agar wisatawan merasa nyaman saat berada di Nusa Penida. 


\section{Kepustakaan}

Cooper, dkk. 1995. Tourism, Principles and Prantice. London. Logman

Demeter, Bratucu, Palade. 2015. Dynamics Of The Youth Travel Market On A Global Level. Bulletin of the Transilvania University of BraşovSeries V: Economic Sciences • Vol. 8 (57) No. 1 - 2015.

Dwiputra. 2013. Preferensi Wisatawan Terhadap Sarana Wisata di Kawasan Wisata Alam Erupsi Merapi. Jurnal Perencanaan Wilayah dan Kota, Vol. 24 No. 1. Badan Perencanaan dan Pembangunan Nasional.

Fernandez, Guzman Antonio Munoz. 2016. Youth And Tourism Perspective. Application To Hostels.Regional and Sectoral Economic Studies Vol. 16-1 (2016).

Hair, J. F. 2006. Multivariate Data Analysis. Edisi 5. Jakarta : Gramedia Pustaka Utama.

Honeyball, Eleanor. 2017. Determining The Motivations of Millennial Travellers In The Context Of Cultural Experiences In Southeast Asia. BA (Hons) International Tourism Management.

Kamus Besar Bahasa Indonesia. 2008. Edisi IV.

Kembaren. 2014. Preferensi Wisatawan Terhadap Kunjungan Wisata Pulau Samosir Dengan Analisis Konjoin. Vol. 02 No. 3. ISSN : 2337-9197. Saintia Matematika.

Kotler, Philip. 2009. Manajemen Pemasaran, Edisi 13. Jakarta : Erlangga

Kusmayadi. 2000. Metodologi Penelitian dalam Bidang Kepariwisataan. Jakarta : PT. Gramedia Pustaka Utama.

Manik, Gayatri. 2016. Faktor Pendorong Dan Penarik Wisatawan Backpacker Mancanegara Berwisata Ke Bali. Jurnal IPTA ISSN : 2338-8633 Vol. 4 No. 2, 2016.
Meilani, Yohana Cahya Palupi. 2016. Identifikasi Aspek Sumber Daya Manusia Pariwisata Subsektor Perhotelan Tanggerang Berdasarkan Persepsi Wisatawan Generasi Millenial. Conference on Management and Behavioral Studies.Universitas Taruma Negara, Jakarta.

Mowen dan Minor, 2012, Perilaku Konsumen Jilid 1, Edisi Kelima (terjemahan), Erlangga, Jakarta.

Nazir, Moh. 2005. Metode Penelitian. Jakarta : Ghalia Indonesia.

Nursusanti. 2005. Atraksi Wisata. Jakarta : Erlangga.

Pendit, I Noman S. 1994. Ilmu Pariwisata Sebuah Pengantar Perdana.Jakarta : Pradnya Paramita.

Pitana, I Gde dan Gayatri G Putu.2005. Sosiologi Pariwisata. Yogyakarta: C.V ANDI OFFSET

Sugiarto, Endar dan Kusmayadi. 2000. Metode Penelitian dalam Bidang Kepariwisataan, Jakarta : PT Gramedia Pustaka Utama.

Sugiyono, 2009, Metode Penelitian Kuantitatif, Kualitatif, dan $R \& D$. Bandung : Alfabeta.

Sugiyono, 2014, Metode Penelitian Kuantitatif, Kualitatif, dan R\&D. Bandung : Alfabeta.

Sumarwan, Ujang. 2012. Riset Pemasaran dan Konsumen. Bogor : IPB Press.

Suwena, I Ketut \& Widyatmaja, I Gst Ngr., 2010, Pengetahuan Dasar Ilmu Pariwisata. Udayana University Press : Denpasar.

World Tourism Organitation (WTO), 1999, InternationalTourismof a Global

Yoeti, Oka A. 1983. Pengantar Ilmu Pariwisata. Bandung : Angkasa.

Zanuar, Zyendira Amanda. 2017. Preferensi Wisatawan Berpasangan Mancanegara 
Jurnal IPTA

p-ISSN: $2338-8633$

Vol. 8 No. 1,2020

e-ISSN: 2548-7930

Terhadap Produk Wisata Di Gili

Trawangan, Lombok Utara, Nusa

Tenggara Barat.Jurnal IPTA. Vol. 5 No.

1, 2017. Fakultas Pariwisata UNUD. 